\title{
Social Behavior Studies: The Influence of The PVT Method on Toddler's Social Behavior Development (Guidance and Counseling)
}

\begin{abstract}
Bagus Satriya Budi
Program Inklusi Yayasan Pendidikan Pelita Bangsa, Indonesia

Satriya.gempar@gmail.com

ABSTRACT

The ideal natural normal birth event, balanced between the size of the fetus and the area of the mother's pelvis, causes optimal stimulation of the vestibular, viseroseptic, and tactile functions to have the perfect chance of developing the Proprioseptic System. Unique Proprioseptics will integrate primitive reflexes into stages; sensomotor, praxis, to representative, then develop cognitive skills into social behavior intelligence that is recorded in the memory of children aged 3-5 years, and have Type I Acrobatic Reaction at the age of 3 months. If not born normal naturally has an acrobatic reaction pattern; Type II, Type III, and Type IV are at risk of experiencing Failure Managing Senses (sensorry process soldered's / SPD) and environmental disturbances (autism spectrum disolder's / ASD). PVT Habilitation Method from the age of 3 months to ensure the formation of the Proprioseptic System, so the results of research on 303 baby samples consist of 10 birth groups (normal, underweight babies, overweight babies, premature, twins, breech, induction, vacuum, forceps, and cesarean), around 151 infants with PVT habilitation do not suffer from SPD and ASD. While the remaining 152 babies, without PVT habilitation, based on acrobatic reactions the results are as follows; Type I only experienced SPD $=0.13 \%$, Type II in addition to SPD $=0.11 \%$, also experienced ASD $=$ $0.09 \%$, Type III in addition to $\mathrm{SPD}=0.24 \%$, also experienced $\mathrm{ASD}=0,16 \%$, and Type IV besides $\mathrm{SPD}=0.15 \%$, also experienced $\mathrm{ASD}=0.50 \%$.
\end{abstract}

Keywords: Vestibular, Viseroseptic, Tactile, Habilitation PVT, and Proprioseptic

\section{INTRODUCTION}

Biomedics is the science that uses basic principles and knowledge; biology, chemistry and physics to explain life phenomena at the level of molecules, cells, organs and intact organisms, their relationship to disorders or diseases and to find and develop appropriate methods and materials to prevent, treat and restore obstacles or damage as the cause (Choi et al., 2014; Roosendaal, 2007, Elmeros and Madsen, 1999; Palomares et al., 2005).

Criteria for Mother and Fetus fulfill the ideal rules referred to are (Dizon-Townson et al., 2005; M.S. et al., 2010): For expectant mothers: Reproduction age 23 - 33 years; enough amount and variety of healthy foods with general BMI 25,4; general height $155,3 \mathrm{~cm}$ or more; the distance between pregnancies of 4 years or more; normal body condition and healthy function; pollution free; and For future fetus babies: Weight between 3,000 - 3,500 grams; body length of $50 \mathrm{~cm}$ or more; head circumference $33.5 \mathrm{~cm}$; the APGAR test scores reached 10; The skeletal and muscle functions are normal both left and right.

\section{LITERATURE REVIEW}

The problem is not all lucky births can fulfill the ideal rules mentioned above, including birth with; Underweight, Premature, Twin, Breech position, Overweight, Hydrocephalus and Fetal Abnormalities (Abubakari et al., 2015; Gemzell and Roos, 1966; Meis et al., 1987; Vikse et al., 2008). Besides that there is birth through action, among others; Forcep, Sectio cesaria, Vacum suction, or Induction of Sintosinon, so it does not get perfect stimulation by the birth of the mother (Deery and Hughes, 2004; Kraft et al., 2009, 2008, Brochet and Dousset, 1999; Farhad, 2019; Melamed et al., 2000). Bilirubin is the result of a rupture of red blood cells due to inadequate blood volume in the baby to cope with new temperature changes outside the uterus, due to cutting the umbilical cord too early (Fevery, 2008; Perlman and Volpe, 2017; Stocker et al., 1987, Ruscio et al., 2008). 


\section{METHOD}

\subsection{Preventive intervention}

The principle of stimulation for alignment is based on the mechanism of development of the Neuropsychobehavior, as follows:

- Begins by the Internal Sensory Sense Organ

System from the Inner of body sense, digestion, cardio vasculair, and breathing which are innervated by 2 autonomic nervous systems: Orthosympathetic nervous system (lateral horn of the spinal cord C8-L1) and parasympathetic arrangement (N III, N VII, N IX, and myelotom lateral horns S2 - S4),

- Then the External Sensory Sense Organ System from the Surface of body sense; skin, pain, touch, heat, cold, rough, smooth, etc. whose supply starts from peripheral to the spinal cord, through the intervertebrae ganglion to the spinal cord toward the spinothalamicus tractus in the spinal cord,

- Ends the Joint Sensory Sense Organ System from the Joint of the body sense; muscles, tendons, and bones, to form a Sense of joints in the body called system

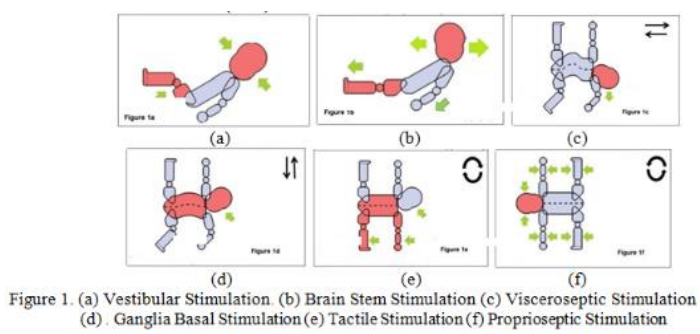

This method should be carried out by his mother which consists of six steps, namely: Step I. Vestibular Stimulation; Step II. Brain Stim Stimulation; Step III. Visceroseptic Stimulation; Step IV. Ganglia Basal Stimulation; Step V. Tactile Stimulation and Step VI. Proprioseptic Stimulation

\subsection{Early detection}

In addition there are also APGAR values that are important, but neglected so that they cannot predict the risk of disruption of social development

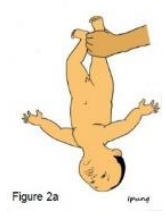

(a)

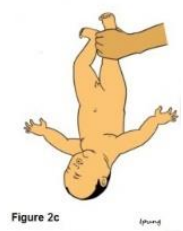

(c)

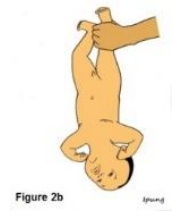

(b)

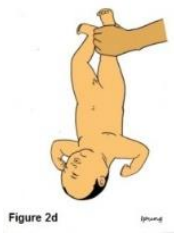

(d)
Figure 2. (a) Type I acrobatic reaction (b). Type II acrobatic reaction (c). Type III acrobatic reactions (d). Type IV acrobatic reaction.

\section{RESULT}

\subsection{Construction and Samples}

The entire cluster is 10 (ten), namely: spontaneous premature $\mathrm{n}=32$ babies, underweight with forcep $\mathrm{n}=$ 32 babies, excess body weight above $3.5 \mathrm{~kg}$ spontaneous $\mathrm{n}=32$ babies, excess body weight with vacuum $n=32$ babies, Cesar section $n=32$ babies, Spontaneous breechus $\mathrm{n}=32$ babies, Spontaneous Jaundice babies $\mathrm{n}=32$ babies and Spontaneous Normal as control $n=32$ babies.

\subsection{Form and Assessment}

In the study, it was stated that the SPD if there were sensomotor obstacles had not continued to praxis, whereas ASD had stated if obstacles had occurred until praxis had continued to be representative.

\subsection{Observation Result}

But the same cluster babies who had Type I, Type II, Type III. Type IV acrobatic reactions without PVT, as table 1 . 
Table 1. Natural Baby Birth Non PVT

\begin{tabular}{|l|c|c|c|c|c|}
\hline \multirow{2}{*}{ NBB } & \multirow{2}{*}{ AR } & \multirow{2}{*}{ PVT } & \multicolumn{3}{|c|}{ Development disorders } \\
\cline { 4 - 6 } & & & Sm & Px & Rp \\
\hline $16 \mathrm{~N}$ & Type I & Not & 1 & 1 & 1 \\
\hline $17 \mathrm{~N}$ & Type I & Not & 1 & 1 & 1 \\
\hline $18 \mathrm{~N}$ & Type I & Not & 3 & 3 & 1 \\
\hline $19 \mathrm{~N}$ & Type I & Not & 1 & 1 & 1 \\
\hline $20 \mathrm{~N}$ & Type I & Not & 1 & 1 & 1 \\
\hline $21 \mathrm{~N}$ & Type I & Not & 1 & 1 & 1 \\
\hline $22 \mathrm{~N}$ & Type I & Not & 1 & 1 & 1 \\
\hline $23 \mathrm{~N}$ & Type I & Not & 3 & 1 & 1 \\
\hline $24 \mathrm{~N}$ & Type I & Not & 1 & 1 & 1 \\
\hline $25 \mathrm{~N}$ & Type I & Not & 1 & 1 & 1 \\
\hline $26 \mathrm{~N}$ & Type I & Not & 1 & 1 & 1 \\
\hline $27 \mathrm{~N}$ & Type I & Not & 1 & 1 & 1 \\
\hline $28 \mathrm{~N}$ & Type I & Not & 1 & 1 & 1 \\
\hline $29 \mathrm{~N}$ & Type I & Not & 1 & 1 & 1 \\
\hline $30 \mathrm{~N}$ & Type I & Not & 1 & 1 & 1 \\
\hline
\end{tabular}

Note

NBB: Natural Baby Birth

AR: Acrobatic Reaction

PVT: Vestibulat - Tactile alignment

Sm Sensomotor

Px: Praxis

Rp: Representative

First, it turns out that these two babies were born two years apart and less than three years (Table 1).

Table 2. High Birth Weight Babies Non PVT

\begin{tabular}{|l|c|c|c|c|c|}
\hline \multirow{2}{*}{ NBB } & \multirow{2}{*}{ AR } & \multirow{2}{*}{ PVT } & \multicolumn{3}{|c|}{ Development disorders } \\
\cline { 4 - 6 } & & Sm & Px & Rp \\
\hline $16 \mathrm{~T}$ & Type II & Not & 3 & 1 & 1 \\
\hline $17 \mathrm{~T}$ & Type II & Not & 3 & 3 & 1 \\
\hline $18 \mathrm{~T}$ & Type II & Not & 3 & 1 & 1 \\
\hline $19 \mathrm{~T}$ & Type II & Not & 3 & 3 & 1 \\
\hline 20T & Type II & Not & 3 & 1 & 1 \\
\hline 21T & Type II & Not & 3 & 1 & 1 \\
\hline 22T & Type II & Not & 3 & 3 & 3 \\
\hline 23T & Type II & Not & 3 & 1 & 1 \\
\hline $24 \mathrm{~T}$ & Type II & Not & 3 & 1 & 1 \\
\hline $25 \mathrm{~T}$ & Type II & Not & 3 & 3 & 1 \\
\hline $26 \mathrm{~T}$ & Type II & Not & 3 & 3 & 1 \\
\hline $27 \mathrm{~T}$ & Type II & Not & 3 & 1 & 1 \\
\hline 28T & Type II & Not & 3 & 3 & 3 \\
\hline $29 \mathrm{~T}$ & Type II & Not & 3 & 3 & 1 \\
\hline $30 \mathrm{~T}$ & Type II & Not & 3 & 1 & 1 \\
\hline
\end{tabular}

Note

HBWB: High Birth Weight BAbies

AR: Acrobatic Reaction

PVT: Vestibulat - Tactile alignment

Sm: Sensomotor

Px: Praxis

Rp: Representative
Second, In the birth of High Birth Weight Babies cluster there were 15 infants with acrobatic type II reactions and two type III infants, but without PVT intervention, then were observed for 30 months against obstacles to sensomotor, praxis and representative development.

Table 3. Low Birth Weight Babies Non PVT

\begin{tabular}{|l|c|c|c|c|c|}
\hline \multirow{2}{*}{ NBB } & \multirow{2}{*}{ AR } & \multirow{2}{*}{ PVT } & \multicolumn{3}{|c|}{ Development disorders } \\
\cline { 4 - 6 } & & & Sm & Px & Rp \\
\hline $16 \mathrm{R}$ & Type III & Not & 3 & 1 & 1 \\
\hline $17 \mathrm{R}$ & Type III & Not & 3 & 1 & 1 \\
\hline $18 \mathrm{R}$ & Type III & Not & 3 & 1 & 1 \\
\hline $19 \mathrm{R}$ & Type III & Not & 1 & 3 & 1 \\
\hline $20 \mathrm{R}$ & Type III & Not & 3 & 1 & 1 \\
\hline $21 \mathrm{R}$ & Type III & Not & 3 & 6 & 3 \\
\hline $22 \mathrm{R}$ & Type III & Not & 3 & 1 & 1 \\
\hline $23 \mathrm{R}$ & Type III & Not & 3 & 1 & 1 \\
\hline $24 \mathrm{R}$ & Type III & Not & 3 & 3 & 3 \\
\hline $25 \mathrm{R}$ & Type III & Not & 3 & 1 & 1 \\
\hline $26 \mathrm{R}$ & Type III & Not & 3 & 3 & 1 \\
\hline $27 \mathrm{R}$ & Type III & Not & 3 & 1 & 1 \\
\hline $28 \mathrm{R}$ & Type III & Not & 3 & 6 & 3 \\
\hline $29 \mathrm{R}$ & Type III & Not & 3 & 1 & 1 \\
\hline $30 \mathrm{R}$ & Type III & Not & 3 & 1 & 1 \\
\hline
\end{tabular}

Note

LBWB: Low Birth Weight BAbies

AR: Acrobatic Reaction

PVT: Vestibulat - Tactile alignment

Sm: Sensomotor

Px: Praxis

Rp: Representative

Third, in the birth of Low Birth Weight Babies cluster of 15 babies born with less weight $(\leq 3,000 \mathrm{~g})$, there were 14 babies who had type III acrobatic reactions and only one baby had type II acrobatic reactions and without PVT. Specifically, two babies among those who have type III acrobatic reactions are babies with birth spacing of less than two years.

Table 4. Sectio Cesaria Birth Babies Non PVT

\begin{tabular}{|l|c|c|c|c|c|}
\hline \multirow{2}{*}{ NBB } & \multirow{2}{*}{ AR } & \multirow{2}{*}{ PVT } & \multicolumn{3}{|c|}{ Development disorders } \\
\cline { 4 - 6 } & & & Sm & Px & Rp \\
\hline 16C & Type IV & Not & 3 & 3 & 3 \\
\hline 17C & Type IV & Not & 3 & 1 & 1 \\
\hline 18C & Type IV & Not & 3 & 3 & 1 \\
\hline 19C & Type IV & Not & 3 & 1 & 1 \\
\hline 20C & Type IV & Not & 3 & 1 & 1 \\
\hline 21C & Type IV & Not & 3 & 3 & 6 \\
\hline 22C & Type IV & Not & 3 & 1 & 1 \\
\hline 23C & Type IV & Not & 3 & 3 & 3 \\
\hline 24C & Type IV & Not & 3 & 1 & 1 \\
\hline
\end{tabular}




\begin{tabular}{|l|c|c|c|c|c|}
\hline \multirow{2}{*}{ NBB } & \multirow{2}{*}{ AR } & \multirow{2}{*}{ PVT } & \multicolumn{3}{|c|}{ Development disorders } \\
\cline { 4 - 6 } & & & Sm & Px & Rp \\
\hline 25C & Type IV & Not & 3 & 3 & 6 \\
\hline 26C & Type IV & Not & 3 & 1 & 1 \\
\hline 27C & Type IV & Not & 3 & 3 & 3 \\
\hline 28C & Type IV & Not & 3 & 1 & 1 \\
\hline 29C & Type IV & Not & 3 & 3 & 1 \\
\hline 30C & Type IV & Not & 3 & 1 & 1 \\
\hline 31C & Type IV & Not & 3 & 3 & 1 \\
\hline
\end{tabular}

Note

SCBB: Sectio Secaria Birth Babies

AR: Acrobatic Reaction
PVT: Vestibulat - Tactile alignment

Sm Sensomotor
Px: Praxis
Rp: Representative

Fourth, the birth of a Sectio Cesaria Birth Babies cluster there were 16 babies who all had a Type IV acrobatic reaction, without PVT intervention and were observed for 30 months against obstacles to sensomotor, praxis and representative development.

\& ASD risk 20\%, and in Sectio CesariaBirth Babies at SPD risk $19 \%$ \& ASD risk $31 \%$.

Table 5. Recapitulation of Result Study of PVT in baby After 30 Month

\begin{tabular}{|c|c|c|c|c|c|c|c|c|c|c|c|c|c|}
\hline \multirow{2}{*}{$\begin{array}{c}\text { Variabl } \\
\text { e of } \\
\text { birth }\end{array}$} & \multirow{2}{*}{$\begin{array}{c}\% \text { age } \\
\text { of } \\
\text { number }\end{array}$} & \multirow{2}{*}{$\begin{array}{c}\text { Number } \\
\text { of birth } \\
\text { for } 2 \\
\text { years } \\
(1987- \\
1989)\end{array}$} & \multirow{2}{*}{$\begin{array}{c}\text { AR } \\
\text { Tes } \\
t\end{array}$} & \multicolumn{4}{|c|}{ Acrobatic Reaction } & \multirow[b]{2}{*}{ PVT } & \multicolumn{2}{|c|}{$\begin{array}{l}\text { Result after } \\
30 \text { month }\end{array}$} & \multirow[b]{2}{*}{$\begin{array}{l}\text { Non } \\
\text { PVT }\end{array}$} & \multicolumn{2}{|c|}{$\begin{array}{l}\text { Result After } \\
30 \text { Month }\end{array}$} \\
\hline & & & & $\begin{array}{l}\text { Type } \\
\text { I }\end{array}$ & $\begin{array}{l}\text { Typ } \\
\text { e II }\end{array}$ & $\begin{array}{l}\text { Typ } \\
\text { e III }\end{array}$ & $\begin{array}{l}\text { Type } \\
\text { IV }\end{array}$ & & $\%$ PSD & $\% \mathrm{ASD}$ & & $\%$ PSD & $\% \mathrm{ASD}$ \\
\hline NBB & 0.59 & 992 & 30 & 30 & & & & 15 & 0 & 0 & 15 & 0.13 & 0 \\
\hline HBWB & 0.11 & 183 & 30 & & 28 & 2 & & 15 & 0 & 0 & 15 & 0.33 & 0.13 \\
\hline VSBB & 0.02 & 35 & 30 & 2 & 26 & 2 & & 15 & 0 & 0 & 15 & 0.13 & 0.27 \\
\hline BBJ & 0.02 & 30 & 30 & & 30 & & & 15 & 0 & 0 & 15 & 0.13 & 0 \\
\hline BBBP & 0.03 & 59 & 30 & & 19 & 11 & & 15 & 0 & 0 & 15 & 0.07 & 0.13 \\
\hline PBB & 0.02 & 36 & 30 & & & 22 & 8 & 15 & 0 & 0 & 15 & 0.13 & 0.27 \\
\hline LBWB & 0.12 & 195 & 30 & & 2 & 28 & & 15 & 0 & 0 & 15 & 0.13 & 0.20 \\
\hline TBB & 0.02 & 41 & 32 & & & 32 & & 16 & 0 & 0 & 16 & 0.25 & 0.06 \\
\hline $\mathrm{BBF}$ & 0.02 & 33 & 30 & & & 28 & 2 & 15 & 0 & 0 & 15 & 0.27 & 0.20 \\
\hline SCBB & 0.05 & 85 & 31 & & & & 31 & 15 & 0 & 0 & 16 & 0.19 & 0.31 \\
\hline Total & 1.00 & 1689 & 303 & 32 & 105 & 125 & 41 & 151 & 0 & 0 & 152 & & \\
\hline \multicolumn{9}{|c|}{ Average number of SPD or ASD } & 0 & 0 & & 0.18 & 0.16 \\
\hline
\end{tabular}

Note

NBB $\quad$ : Natural Baby Birth

VSBB : Vacuum Suction Birth Babies

BBJ : Babies Born Jaundice

PBB : Premature Birth Babies

LBWB : Low Birth Weight Babies

BBF : Baby Born with Forcep

SCBB : Sectio Cesaria Birth Babies
HBWB : High Birth Weight Birth

BBBP : Baby Born Breech Position

TBB : Twin Birth Babies

\section{DISCUSSION}

The results of the recapitulation of all clusters, showed that the group that received the habilitation PVT intervention experienced good development, on time at the sensomotor, praxis and representative stages.
Table 7. Analysis Base on Acrobatic Type

\begin{tabular}{|c|c|c|c|c|c|c|}
\hline AR & PVT & SPD & ASD & $\begin{array}{c}\text { Non } \\
\text { PVT }\end{array}$ & SPD & ASD \\
\hline Tipe I & 16 & 0 & 0 & 16 & 0.13 & 0 \\
\hline Tipe II & 53 & 0 & 0 & 53 & 0.15 & 0.06 \\
\hline Tipe III & 62 & 0 & 0 & 63 & 0.15 & 0.50 \\
\hline Tipe IV & 20 & 0 & 0 & 20 & 0.15 & 0.50 \\
\hline Total & 151 & 0 & 0 & 152 & 0.66 & 0.72 \\
\hline Average & & 0 & 0 & & 0.17 & 0.18 \\
\hline
\end{tabular}






Figure 3.Uterine Contraction for Vestibular Stymulan

Types I and II are generally experienced by babies with normal natural birth, which is preceded by the effect of the hormone oxytosis up to a minimum of 8 hours of adequate uterine contractions from moderate to strong rhythmically (Figure 3).

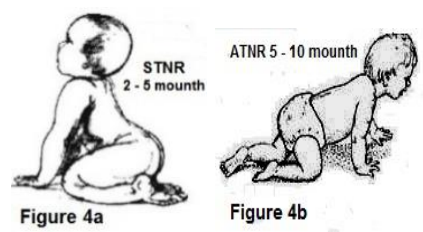

Figure 4. (a) STNR (b) ATNR

The SPD and ASD are conditions that are not optimal development of basic cognitive skills, so that children become delay in performance and are not eligible if they enter formal school.

\section{CONCLUSION}

Habilitation PVT interventions are proven as prevention of developmental disorders for babies who have type II, III, and IV acrobatic reactions so that the development of STNR and ATNR is timely, so that PROPRIOSEPTIC patterned as a UNIQUE of the individual joint sense in stimulating normative cognitive skills in the social field and education.

\section{REFERENCES}

[1] Aizhen Yang1 and Timothy E. Hullar, 2007;" Relationship of Semicircular Canal Size to Vestibular-Nerve Afferent Sensitivity in Mammals" Department of Otolaryngology-Head and Neck Surgery and 2 Department of Anatomy and Neurobiology; Washington University in St. Louis School of Medicine, St. Louis, Missouri

[2] Asim K Dutta-Roy, Am J Clin Nutr 2000; "Transport mechanisms for long-chain polyunsaturated fatty acids in the human placenta", American Society for Clinical Nutrition
[3] Ayres, A.J. (1989). Sensory Integration and Praxis Tests. Los Angeles, Western Psychological Services.

[4] Bernard J, Baars and Nicole M Gage,2010; "Cognition, Brain and Consciousness, Introduction to Cognitive Neuroscience", Second Edition, British Library Cataloguing in Publication Data

[5] Bao-Ping Zhu, M.D., Robert T. Rolfs, M.D., M.P.H., Barry E. Nangle, Ph.D., And John M. Horan, M.D., M.P.H. 1999; "Effect of The Interval Between Pregnancies on Perinatal Outcomes", the Massachusetts Medical Society

[6] Callaghan, T. C. (2005). "Cognitive Development Beyond Infancy. In B. Hopkins (Ed.), The Cambridge Encyclopedia of Child Development" (pp. 204-209). Cambridge, UK: Cambridge University Press

[7] Carissa J. Cascio, 2010; Somatosensory processing in neurodevelopmental disorders, Vanderbilt Kennedy Center for Research on Human Development, Vanderbilt University Department of Psychiatry, Nashville.

[8] Carlson NR; Physiology of behavior 4 th Edition. Allyn and Bacon. Boston, London, Toronto, Sydnney, Tokyo, Singapura.

[9] Dorothea M. Moorea, Anila M. D’Melloa, Lauren M. Mc Grathb,c,d, Catherine J. Stoodley, 2016; "Developmental Cognitive Neuroscience, The developmental relationship between specific cognitive domains and grey matter in the cerebellum", Department of Psychology, University of Denver, Denver, Washington, DC, USA.

[10] Dr. Silvia Helena Cardoso, PhD, 1997; “ Connections of the Basal Ganglia", Center for Biomedical Informatics,State University of Campinas, Brazil.

[11] Elaine Aron, Ph.D., Barbara Allen-Williams, and Jacquelyn Strickland, LPC (2016): FAQ: Is Sensory Processing (or Integration) Disorder (SPD) the same as Sensory Processing Sensitivity (SPS).

[12] Elizabeth O. Johnson, PhD, 2010; "Proprioceptic", Center for International Rehabilitation Research 
Information and Exchange, University at Buffalo, The State University of New York

[13] Erikson, E. H, 1993;"Childhood and society, WW Norton \& Company.

[14] Fisher, A., Murray, E., \& Bundy, A. 1991; "Sensory Integration Theory and Practice". Philadelphia: F.A. Davis Company. Troy University

[15] Hope Weiler, ShirleyFitzpatrick-Wong, Jeannine Schellenberg, Ursula Mccloy, Rebecca Veitch, Heather Kovacs, June Kohut, Chui Kin Yuen, 2005 ; "Mathernal and Coord Blood Long ChainPolyunsaturated Fatty Acids are Predictive of Bone Mass at Birth in Healthy Term Born-Infant", Human Nutritional Sciences and $\uparrow$ Pediatrics and Child Health, University of Manitoba, Winnipeg, Canada

[16] Jen Danna, 2011 ; How to Estimate Epiphyseal Fusion , Forensics 101

[17] Julie Davanzo, Lauren Hale , Abdur Razzaque \& Mizanur Rahman (2008); The effects of pregnancy spacing on infant and child mortality in Matlab, Bangladesh: How they vary by the type of pregnancy outcome that began the interval, Population Studies

[18] Kay C. Wood, HarlanSmith, and Daurice Grossniklaus. 2012; "Piaget's Stages of Cognitive Development". pp. 6 [5]Department of Educational Psychology and Instructional Technology, University of Georgia

[19] Korhonen, Ulla.; "Maternal pelvis, feto-pelvic index and labor dystocia". University of Eastern Finland, Faculty of Health Sciences,Publications of the University of Eastern Finland. Dissertations

[20] in Health Sciences Number 244, 2014, 52 p.

[21] K Tan, G Yeo, 2008;'Influence of Maternal Height, Weight, and Body Mass Indexs on Birthweight in an Asia Population", The Internet Journal of Gynecology and Obstetric Frame of Reference. in Pediatric Occupational Therapy", Philadelphia

[22] Kolb, B., \& Whishaw, I. Q. (2009); "Fundamentals of human neuropsychology". 6th Edition, New York, NY: Worth Publishers

[23] Larson, K.A. (1982). The Sensory History of developmentally Delayed Children With and Without Tactile Defensiveness. American Journal of Occupational therapy 36, pp 590-596.

[24] Lincoln Gray, Ph.D., 2013; "Vestibular System: Structure and Function" Department of Communication Sciences and Disorders, James Madison University

[25] Luria AR; The Working Brain, Simon and Schuster, New York
[26] Mohsen Jamali, Soroush G. Sadeghi, and Kathleen E. Cullen, 2009;" Response of Vestibular Nerve Afferents Innervating Utricle and Saccule During Passive and Active Translations", the American Physiological Society

[27] M.-Marsel Mesulam, 2000; "Principles of Behavioral and Cognitive Neurology", Second Edition, Oxford University Press, Inc.

[28] May-Benson, T. A., \& Cermak, S. A. (2007) Development of an assessment for ideational praxis. American Journal of Occupational Therapy, 61, 148-153

[29] Martínez-Frías ML1, Rodríguez-Pinilla E, Bermejo E, Prieto L, 2002: Epidemiological evidence that maternal diabetes does not appear to increase the risk for Down Syndrome. Am J Med Genet

[30] Natasha Campbell Mc Bridge, 2010;"Gut and Psychology Syndrome: Natural Treatment for Autism, Dyspraxia, A.D.D., Dyslexia, A.D.H.D, Depression, Schizophrenia" UK

[31] Neil R. Carlson 2017, Allyn and Bacon ;"Physiology of Behavior". (11th Edition) Boston

[32] Pinel PJ; Biopsychology, Allan and Bacon, Boston, London, Sydney, Toronto.

[33] Paula de Prado Bert, Elisabet Mae Henderson Mercader, Jesus Pujol, Jordi Sunyer, and Marion Mortamais;" The Effects of Air Pollution on the Brain: a Review of Studies Interfacing Environmental Epidemiology and Neuroimaging" Curr Environ Health Rep. 2018; 5(3): 351-364. Published online 2018 Jul 14. Barcelona, Spain

[34] Quick Tips, 2013 ; How To Estimate The Chronological Age Of A Human Skeleton Epiphyseal Closure Method For juicy tidbits of information and insights into the world that involves archaeological, anthropological and forensic sciences

[35] Restak RM; The Brain, The Last Frontier, Warmwer Books. New York

[36] Royeen, C.B (1985). Domain Specifications of the Construct Tactile Defensiveness. In: Fisher, E. Murray \& Bundy, A (Eds). Sensory Integration: Theory and Practice. Philadelphia: F A Davis

[37] Raymond A. Sturner, Mark Horton, Sandra C. Funk, Joanne Barton, Thomas E. Frothingham, Joseph N. Cress, 1982;"Adaptations of the Denver Developmental Screening Test: A Study of Preschool Screening". the American Academy of Pediatrics, From the Department of Pediatrics, Duke University Medical Center, Durham, North Carolina. 